\title{
Erratum: Authorship Correction
}

https://doi.org/10.4163/jnh.2018.51.6.538

Journal of Nutrition and Health (J Nutr Health) 2018; 51(6): $538 \sim 555$

\section{Association of coffee consumption with health-related quality of life and metabolic syndrome in Korean adults: based on $2013 \sim 2016$ Korea National Health and Nutrition Examination Survey}

Kim, Hyesook $\cdot$ Kim, Yu Jin $\cdot \operatorname{Lim}$, Yeni $\cdot$ Kwon, Oran ${ }^{\dagger}$

Department of Nutritional Science and Food Management, Ewha Womans University, Seoul 03760, Korea

The original version of this article contained an error in authorship. The correct information of authorship should be as follows. The authors would like to apologize for any inconvenience caused.

- After correction

Kim, Hyesook $\cdot$ Kim, Youjin $\cdot$ Lim, Yeni $\cdot$ Kwon, Oran ${ }^{\dagger}$

Department of Nutritional Science and Food Management, Ewha Womans University, Seoul 03760, Korea

\footnotetext{
$\dagger$ To whom correspondence should be addressed. tel: +82-2-3277-6860, e-mail: orank@ewha.ac.kr commons. org/licenses/by-nc/3.0/) which permits unrestricted non-commercial use, distribution, and reproduction in any medium, provided the original work is properly cited.
} 